\title{
A Study on Hardness and Wear behaviour of Untreated and Cryogenically Treated AI-SiC and Al-Gr Metal Matrix Composite
}

\author{
G. B. Krishnappa ${ }^{1}$, Arunkumar K. N. ${ }^{{ }^{*}}$ and Mohammed Salman Pasha ${ }^{1}$ \\ ${ }^{1}$ Department of Mechanical Engineering, VVCE, Mysuru - 570002, INDIA
}

\begin{abstract}
The present study aims at evaluating the hardness and wear behaviour of untreated and cryogenically treated aluminium-silicon carbide and aluminium graphite metal matrix composite. In this composite Al6061 is used as matrix material with varying Silicon carbide quantity from $2.5 \mathrm{wt} \%$ to $10 \mathrm{wt} \%$ and also varying the quantity of graphite from $1 \mathrm{wt} \%$ to $4 \mathrm{wt} \%$. The composites used for this study were fabricated using stir casting technique. Electron dispersive X-ray spectroscopy and X-ray diffraction tests were carried out to know the composition and phase identification of the composite sample. Microstructure analysis was carried out to study the structure of the composites with and without cryogenic treatment. Hardness behaviour of a metal plays a vital role in understanding the resistance offered by a particular metal to the various shape changing forces and the ability of the metal to resist deformation. Similarly, wear is erosion of material from its original position on a solid surface performed by the action of any other material surface. It is very important to know the wear property of any given material in order to gain an understanding of the wear process, to determine the effects of variables, to characterize materials, and to select materials for specific applications.
\end{abstract}

Keywords: Al6061+SiC, Al6061+Gr , Cryogenic treatment

\section{Introduction}

\subsection{Composites}

In recent decades, composite materials have effectively submitted the customary materials in a few light weight and high quality applicants. A composite material is a material which is made from two or more constituent materials with different properties that, when combined together, produce a material with unique characteristics. Composite material consists of two phases, primary phase and secondary phase. Matrix forms the primary phase within which secondary phase is imbedded. The embedment is also known as reinforcement or secondary phase. Metal Matrix composite is composite material which consists of at least two constituent parts, one being a metal and other may be a different metal or any material, such as polymer or organic compound. These are advanced materials giving

* Corresponding author: arunkn.10@vvce.ac.in 
properties that have not accomplished by customary materials. MMCs are generally prepared by dispersing the reinforcements in metal matrix. The alloys of aluminium, magnesium, titanium, and copper, are chosen as matrix material. The reinforcement is in the form of both continuous and discontinuous fibres, whiskers, and particulates. Aluminium metal matrix composites are light weight and high performance aluminium centric material system. Aluminium metal matrix composites generally utilized in high-tech structural and functional applications including defence, aerospace, automotive, and thermal management areas and sports. AMCs are anticipated to replace monolithic materials incorporating aluminium alloys, ferrous alloys, titanium alloys and polymer based composites in a number of appliances.

\subsection{Fabrication of metal matrix composites}

There is an extensive choice of creation methods in favour of composite materials yet here emphasis will be on the creation of MMCs and particularly particulate reinforced composites.

On the account of creation of MMC's, there are two stages existing. They are: matrix phase and reinforcement phase. Metal or an alloy of a base metal constitute matrix phase and the ceramic generally stand for reinforcement phase. Mechanically combined matrix and reinforcement is called MMCs. If it is not mixed mechanically, the product will be an alloy, not a composite material. In our study, aluminium metal matrix composites were synthesized using stir casting method.

\subsection{Cryogenics}

The utilization of thermal treatments to enhance mechanical properties of metal components is an antiquated craftsmanship from the previous eras and is used till date. The treatments that are applied to metals to enhance mechanical properties are in a choice of temperature higher than the room temperature. Since few decades, attention has been shown in the cause of sub-zero treatment on the performance of metals. Sub-zero treatment is generally classified as either cold treatment down to dry ice temperature $193 \mathrm{k}$ or deep cryogenic treatment at near liquid nitrogen temperature $77 \mathrm{k}$.

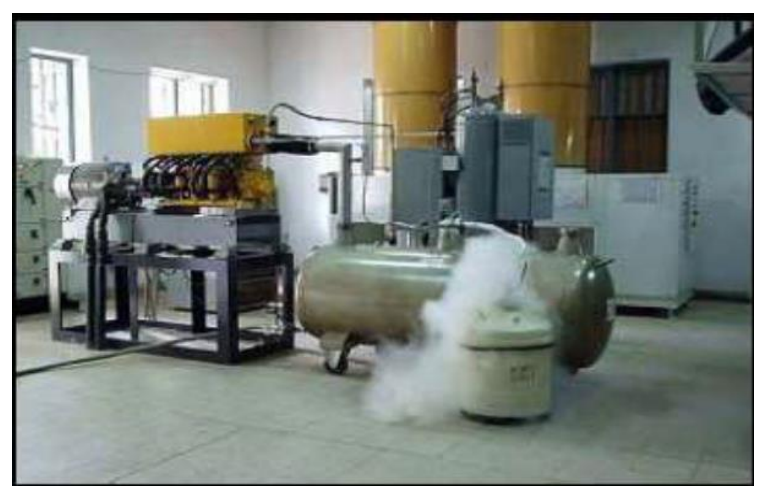

Fig. 1. Cryogenic Treatment Equipment 


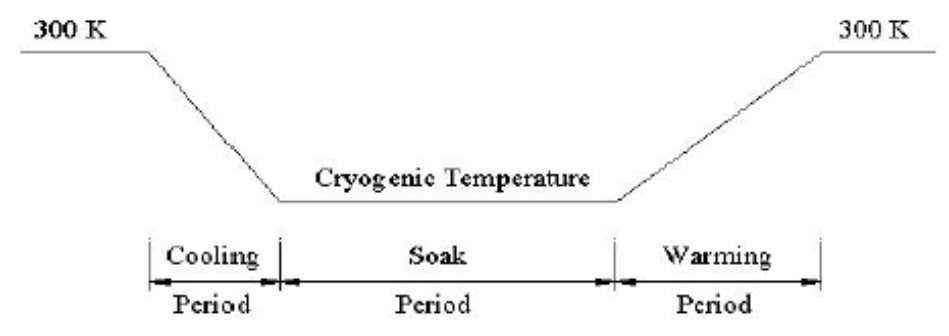

Fig. 2. Cryogenic Treatment Cycle

Cryogenic treatment imparts no visible changes in the metal after treatment. Despite the fact that it is unrealistic to observe external physical changes in the metal, a more uniform and refined microstructure with greater density is observed through metallurgical microscopes.

Typically, cryogenic treatment cycle comprises of cooling the test specimens from room temperature to cryogenic temperature in around 4 hours followed by soaking it at cryogenic temperature (normally liquid nitrogen temperature) for around 24hours and then warming it to room temperature for about 9 hours. The soak temperature and duration are to a great extent in charge of changes in the properties after cryogenic treatment.

\section{Materials used}

\subsection{Materials}

The raw materials as well as reinforcement materials used in synthesis of AMMCs are briefly described below.

\subsubsection{Al6061}

The aluminium Al6061 grade was utilized as the matrix material. Still some compelling studies are being conducted on aluminium alloys. It has low density, which gives additional positive circumstances in a couple of utilizations. Cast iron and Bronze have been supplanted by aluminium alloys to make wear resistance parts. 
Table 2. Chemical Composition of Al6061 by Wt $\%$

\begin{tabular}{|l|l|}
\hline Elements & Percentage \\
\hline $\mathrm{Al}$ & 97.01 \\
\hline $\mathrm{Mg}$ & 0.88 \\
\hline $\mathrm{Si}$ & 0.71 \\
\hline $\mathrm{Fe}$ & 0.64 \\
\hline $\mathrm{Cu}$ & 0.23 \\
\hline $\mathrm{Cr}$ & 0.15 \\
\hline $\mathrm{Ti}$ & 0.04 \\
\hline $\mathrm{Zn}$ & 0.09 \\
\hline $\mathrm{Mn}$ & 0.11 \\
\hline
\end{tabular}

Fig. 3. Aluminium 6061 Ingot

\subsubsection{Silicon Carbide}

Silicon carbide (Sic) can be utilized as a reinforcement in the form of particulars, whiskers or fibres to enhance the properties of the composite. SiC improves the overall strength of the composites along with very high wear resistance and corrosion. The wear resistance of carbides is very high, therefore the wear resistance of material obtained is also high. Also, the hardness of the composites will increase. SiC are harder than Aluminium metals. If we add $\mathrm{SiC}$ in aluminium then it increases the stiffness of the material. After adding hard reinforcement, it resulted in improvement in resistance to wear and abrasion of the material. Content of $\mathrm{SiC}$ in material must be carefully added to avoid problem of grain boundaries, embrittlement and cracks formations.

Table 3. Properties of Silicon Carbide (SiC)

\begin{tabular}{|l|c|}
\hline Properties & Values \\
\hline Elastic Modulus(Gpa) & 410 \\
\hline Density(g/cc) & 3.1 \\
\hline Poisson's ratio & 0.14 \\
\hline Hardness(HB500) & 2800 \\
\hline Compression Strength(Mpa) & 3900 \\
\hline Melting temperature $\left({ }^{\circ} \mathrm{C}\right)$ & 3100 \\
\hline
\end{tabular}

Fig. 4. Silicon Carbide Powder

\subsubsection{Graphite}

Graphite is a crystalline form of carbon having a layered structure with sheets of closely arranged carbon atoms. Consequently, graphite is fragile when sheared along the layers. This characteristic in turn gives graphite its low frictional properties as a solid lubricant. Its 
frictional properties are low only in an air or moisture. Unlike other materials, strength and stiffness of graphite increases with temperature.

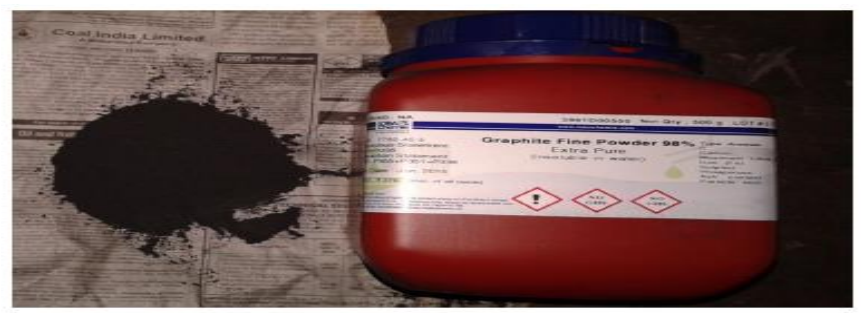

Fig. 5. Graphite Powder

\section{Methodology}

In order to carry out study on hardness and wear behaviour of both cryotreated and untreated AMMCs following methodology was followed. (i) Selection of material: This phase was carried out to select the best material available to reinforce with aluminium. By its application it has decide to $\mathrm{SiC}$ and graphite as reinforcement. Because $\mathrm{SiC}$ acts as binding agent and give good strength and graphite acts as good lubrication agent. (ii) Synthesis of specimen: In this study, stir casting method was used to synthesize Al6061$\mathrm{SiC}$ and Al6061-Gr composites. (iii) Cryogenic treatment: Specimens obtained by synthesizing were made to go through cryogenic treatment in order to manipulate the physical properties. (iv) Tensile and Shear test: Both cryotreated and untreated specimens with $\mathrm{SiC}$ weight fraction of $2.5 \mathrm{wt} \%, 5 \mathrm{wt} \%, 7.5 \mathrm{wt} \%$ and $10 \mathrm{wt} \%$ and $\mathrm{Gr}$ weight fraction of $1 \mathrm{wt} \%, 2 \mathrm{wt} \%, 3 \mathrm{wt} \%$ and $4 \mathrm{wt} \%$ were made to undergo various tensile test and also shear test was carried out on the specimens and results were recorded. (v) Comparison of results: After carrying out various tests on both cryotreated and untreated specimens, results were recorded and compared with each other.

\section{Wear and Hardness test}

Both treated and untreated specimens of AMMCs are subjected to wear and hardness test. Wear test is conducted using a tribometer which is an instrument that measures the tribological quantities like co-efficient of friction, friction force and wear volume between two surfaces in contact. Similarly, to carryout hardness test "Rockwell Hardness Testing Equipment" is used. Readings are recorded for both treated and untreated specimens and compared

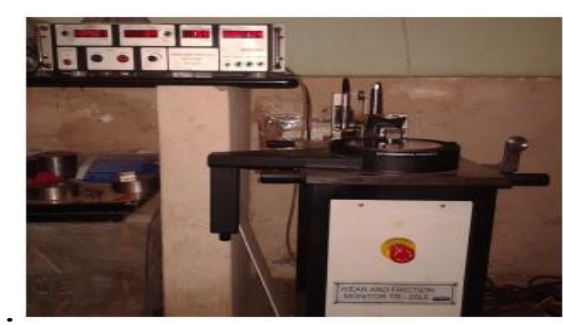

Fig. 6. Wear testing Setup

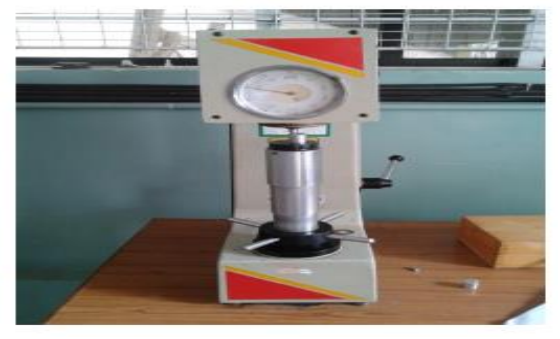

Fig. 7. Rockwell Hardness Testing Equipment 


\section{Results and discussion}

\subsection{Scanning Electron Microstructure}

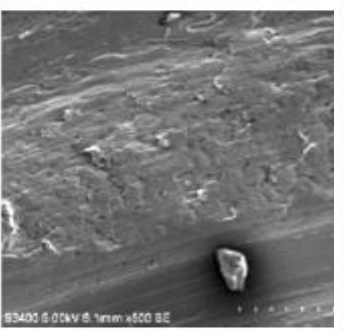

(a)

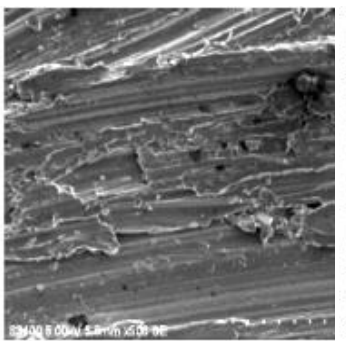

(b)

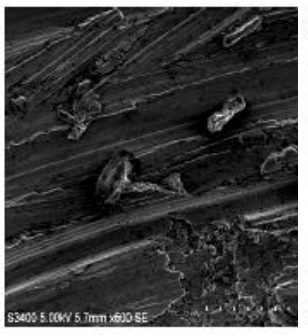

(c)

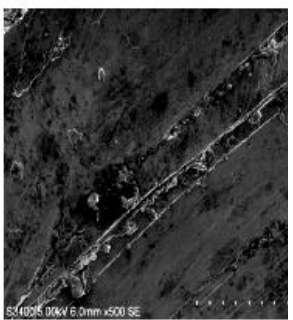

(d)

Fig. 8. SEM of Untreated (a) Al6061+2\% Gr (b) Al6061+4\% Gr (c) Al6061+5\% SiC

(d) $\mathrm{A} 16061+10 \% \mathrm{SiC}$

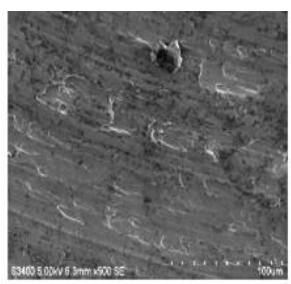

(a)

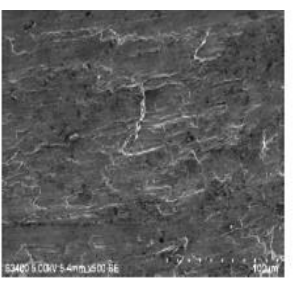

(b)

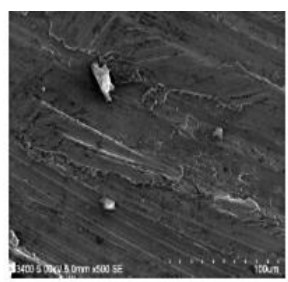

(c)

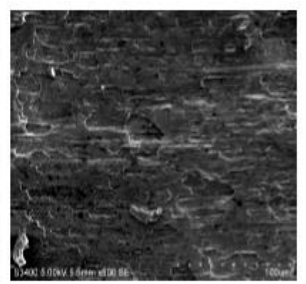

(d)

Fig. 9. SEM of Cryo-treated (a) Al6061+2\% Gr (b) Al6061+4\% Gr (c) Al6061+5\% SiC (d) $\mathrm{Al} 6061+10 \% \mathrm{SiC}$

\subsection{Wear and Co-efficient of friction:}

The tribological behaviour of metal matrix composite was studied using a pi-on-disc tribometer developed according to ASTM G99. The surface of $25 \mathrm{~mm}$ Length and $10 \mathrm{~mm}$ diameter comes in contact with the hardened steel disc of hardness 62 HRC. The test was conducted on a track of $120 \mathrm{~mm}$ diameter, velocity $1 \mathrm{~ms}-1$, time $15 \mathrm{~min}$ and load $20 \mathrm{~N}$.

Wear in the case of $\mathrm{Al}+\mathrm{Gr}$, showed a varying reading for cryotreated and untreated $\mathrm{Al}+\mathrm{Gr}$. Whereas in the case of $\mathrm{Al}+\mathrm{SiC}$, wear values for cryotreated increased when compared to untreated $\mathrm{Al}+\mathrm{SiC}$. Among different weight fraction of $\mathrm{Gr}$ in $\mathrm{Al}+\mathrm{Gr}$, wear property of untreated $\mathrm{Al}+\mathrm{Gr} 3 \%$ was increased significantly compared to cryotreated $\mathrm{Al}+\mathrm{Gr} 3 \%$. Similarly, In the case of $\mathrm{Al}+\mathrm{SiC}$, Wear values of $\mathrm{Al}+\mathrm{SiC} 5 \%$ showed a significant change from 58 micrometres to 248 micrometres. Coefficient of friction values of Cryotreated and untreated $\mathrm{Al}+\mathrm{SiC}$ and $\mathrm{Al}+\mathrm{Gr}$ were recorded. Among all the weight fractions, $\mathrm{Al}+\mathrm{SiC} 7.5 \%$ showed appreciative change in coefficient of friction. 


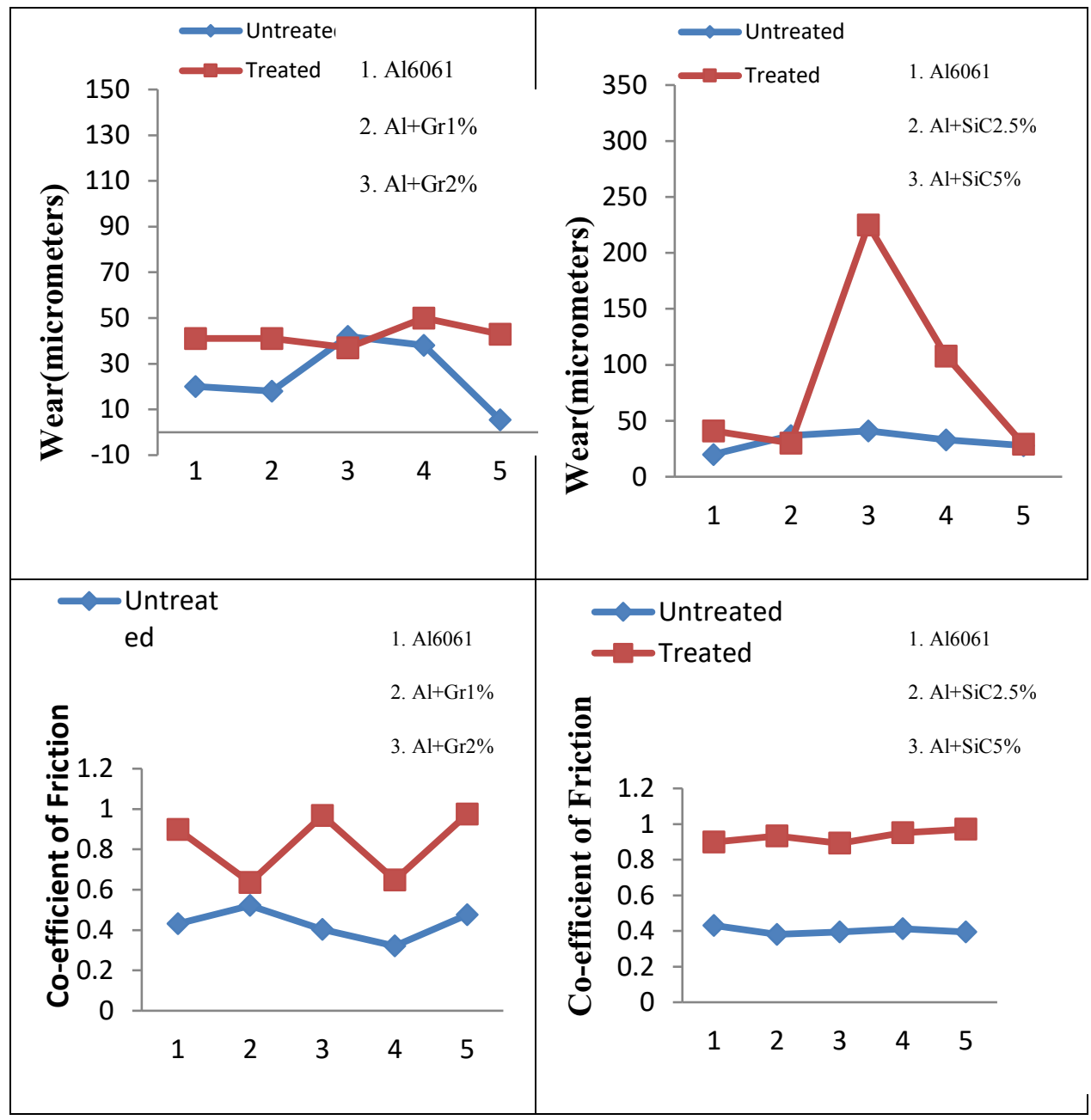

Fig. 10. Wear and co-efficient of friction plot of $\mathrm{Al}+\mathrm{Gr} \mathrm{AMMCs}$

Fig. 11 Wear and Co-efficient of friction plot of $\mathrm{Al}+\mathrm{SiC}$ AMMCs

\subsection{Energy Dispersive Spectroscopy(EDS) Analysis:}

Energy dispersive spectroscopy analysis of the Al6061 reinforced with $\mathrm{Gr}$ and $\mathrm{SiC}$ with weight fraction of $2 \%$ and $5 \%$ respectively. It is shown that $\mathrm{Al}, \mathrm{Si}, \mathrm{O}$ and $\mathrm{C}$ peaks the graph and EDS analysis depicts the presence of AL6061, SiC, Gr particles. The Mg2Si (magnesium silicate) and $\mathrm{SiO} 2$ (silicon oxide) are the products of reaction which shown as $\mathrm{Mg}$ and Si peaks in EDS graph after cryogenic treatment. 


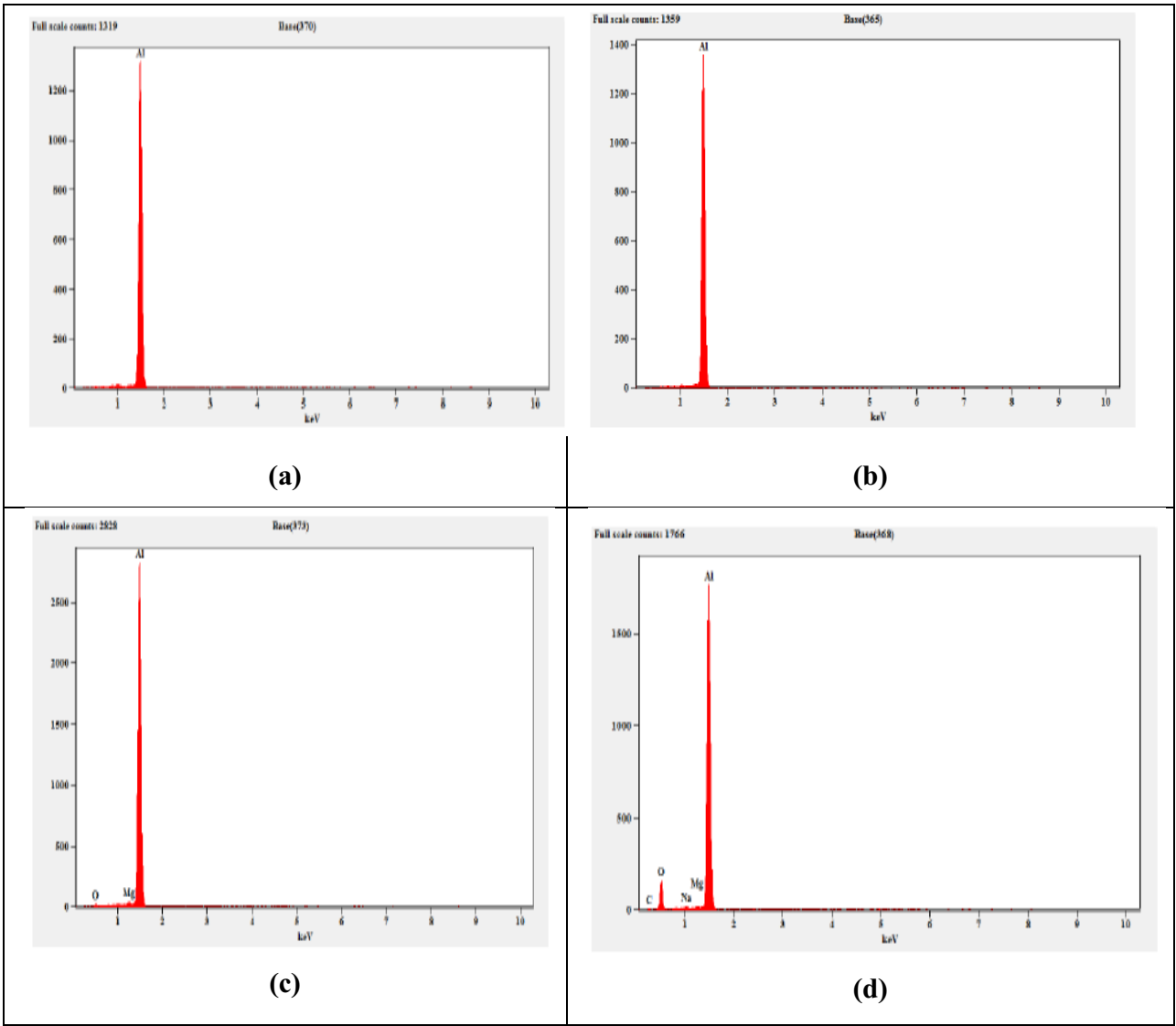

Fig. 12. EDS of (a) Untreated Al6061+ $2 \% \mathrm{Gr}$ (b) Cryo-treated Al6061+2\%Gr (c) Untreated Al6061+5\% SiC (d) Cryo-treated Al6061+5\% $\mathrm{SiC}$

\subsection{Hardness Test}

Hardness measurement is conducted by using Rockwell hardness testing machine. The surface being tested generally requires a metallographic finish and it was done by using 600 and 100 grit size emery paper. Load used on Rockwell's hardness tester was $100 \mathrm{~kg}$ at dwell time of 10 seconds for each sample. It was observed that hardness of cryotreated $\mathrm{Al}+\mathrm{SiC}$ was increased. Similarly, hardness values for both cryotreated and untreated $\mathrm{Al}+\mathrm{Gr}$ was less deviating and was found me almost near to each other. Among all the AMMCs, $\mathrm{Al}+\mathrm{SiC} 7.5 \%$ showed the significant change in hardness value from 190 to 212 . 


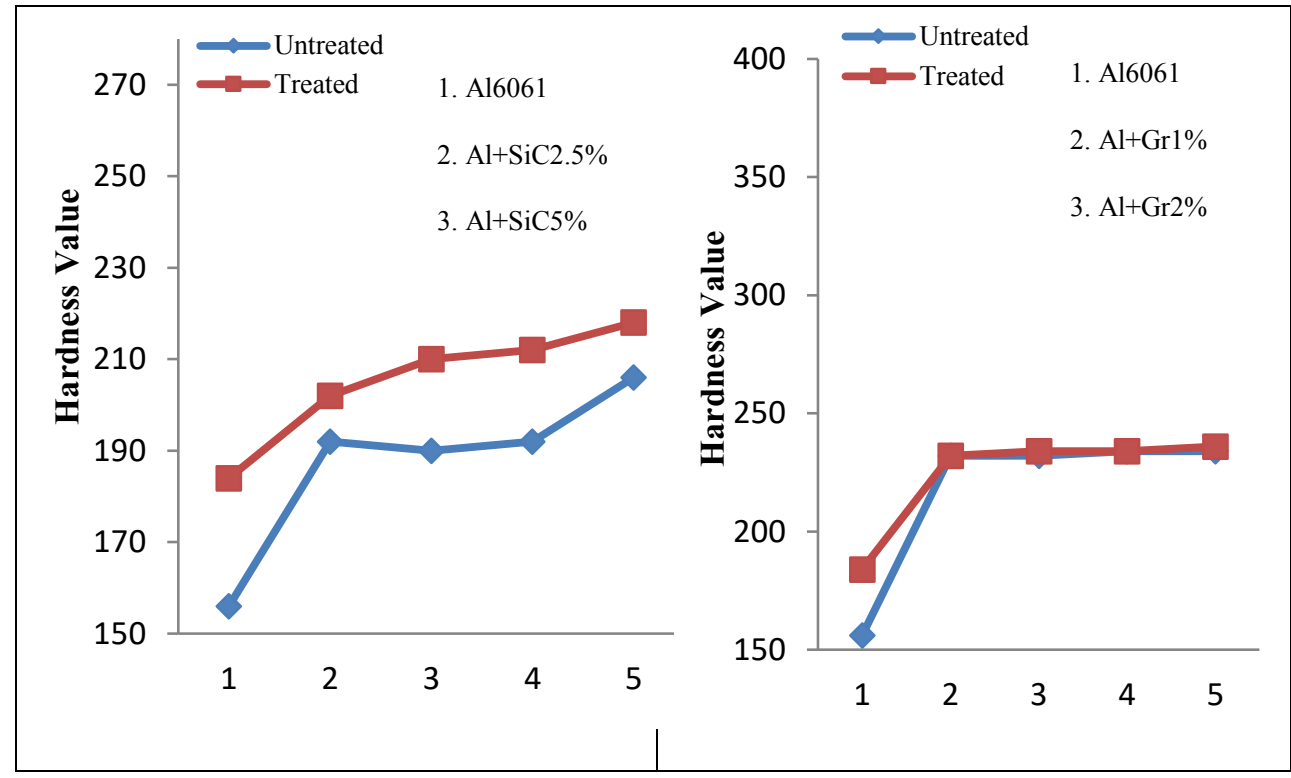

Fig. 13: Hardness Value of $\mathrm{Al}+\mathrm{SiC}$

Fig. 14. Hardness Value of $\mathrm{Al}+\mathrm{Gr}$ AMMCs

\section{Conclusions}

1. Hardness of composites have been increased upto 2-3\% after cryogenic treatment

2. In wear test, the weight loss of alloy and composites material has been decreased after cryogenic treatment

3. SEM images shows a uniform distribution of reinforcement in the material after cryogenic treatment

4. Finally, cryogenic treatment shows an improvement in the microstructure, wear and hardness of AMMCs

\section{References}

1. G. Chigal, G. saini, "Mechanical testing of Al6061/silicon carbide metal matrix composites", IJREAS Volume 2, Issue 2 February (2012) pp 221-238

2. J T. Black, Ronald A. Kohser "Materials and process in manufacturing", Text book tenth edition (2007), pg 351.

3. Seymour. G Epstein, "Aluminium and its alloys", the Aluminium association, (Inc.2001)

4. Surappa.M.K “Aluminium Matrix Composites Challenges and Opportunities”, Sadhan, Vol.28, Parts 1 and 2, (2003), pp319-334

5. Prashant S N, Madev Nagaral, V Auradi, "Preparation and evaluation of mechanical and wear properties of Al6061 reinforced with graphite and SiC particulate metal metal matrix composites", Vol. 1, No. 3, October (2012) IJMERR, pp 106-112 
6. Rajender singh, Yogesh Sharma, Vikas Sharma, "Examine of Mechanical Properties of microstructure, mechanical and fracture properties of Al2O3 metal matrix composites" IJRET Vol. 1, Issue 2, July (2013), pp193-198 